\title{
A REVIEW OF EMPIRICAL MODELS OF SORPTION ISOTHERMS OF HYDROPHOBIC CONTAMINANTS
}

\author{
G. M. Mafuyai \\ Department of Chemistry Faculty of Natural Sciences, University of Jos, Jos Nigeria \\ Correspondence E-mail: godwinmaf@mail.com
}

Cite this article:

G. M. Mafuyai (2021), A Review of Empirical Models of Sorption Isotherms of Hydrophobic Contaminants. African Journal of Environment and Natural Science Research 4(3), 16-44. DOI: 10.52589/AJENSROZHQQUMW.

\section{Manuscript History \\ Received: 10 May 2021 \\ Accepted: 13 June 2021 \\ Published: 12 July 2021}

Copyright $\odot 2020$ The Author(s). This is an Open Access article distributed under the terms of Creative Commons AttributionNonCommercial-NoDerivatives 4.0 International (CC BY-NC-ND 4.0 ), which permits anyone to share, use, reproduce and redistribute in any medium, provided the original author and source are credited.
ABSTRACT: Renewed focus on empirical models of sorption isotherms of hydrophobic organic contaminants (HOCs) onto mineral surfaces and soil components is required because of the importance attached to numerous pollutants released into the environment. This examines the various models and isotherms with their assumptions by different scholars on the contribution of sorption of contaminants onto clay mineral sorbents and soil organic matter with the possible ways of prevention of environmental contamination by HOCs. Literature indicated that empirical models and isotherms have been used to ascertain several surfaces that can be sorbed by hydrophobic organic contaminants. These models also show that soils can retain HOCs even at low soil organic levels and the extent depends on the structure of the pollutant type and concentration of clay minerals in the sorbent. It also revealed the important role played by soil organic carbon in the sorption of contaminants onto soils and how it is strongly affected by the nature and structure of the organic soil matter. Contamination by different pollutants required a renewed approach in the context of the sorption of organic pollutants onto clay minerals from aqueous and non-aqueous solutions.

KEYWORDS: Models, Sorption Isotherms, Hydrophobic Organic Contaminants, Non-Aqueous Phase Liquids. 


\section{INTRODUCTION}

The increasingly widespread occurrence of groundwater and soil contamination has fostered a general need for a better understanding of factors which control the fate of contaminants and their transport in the environment. These organic compounds are major causes of groundwater and soil pollution in which sorption is one of several reactions and mechanisms of transformation which impact movement and fate (Cass and Walter, 1986). Hydrophobic organic contaminants made their way into the soil and sediments as a result of increased industrial use of these organic chemicals (HOCs), along with increased exposure of environmental and agricultural systems to them (Ren. and Schultz, 2002). Many countries of the world nowadays use a large number of these compounds (HOCs) domestically, industrially, and commercially in their daily life as such many are found in topsoil and waterways where they end up after accidental spillage or leaks from waste disposal sites (Manz et al. 2001; Clark et al.1995).Soils and sediments are the ultimate sink for many hydrophobic organic contaminants (Francis et al., 2014).2The concentrations of these HOCs has become the focus of many researchers in which the realistic endpoints for remediation processes depending highly on the availability of these HOCs. Hydrophobic organic compounds include; aromatic compounds in petroleum and fuel residues, chlorinated compounds in commercial solvents and chemicals. The increasing high spread of groundwater contamination has fostered a general need for a better understanding of factors which control the contaminant fate and transport in subsurface environments. Hydrophobic organic compounds being a major class of groundwater pollutants, sorption is the most significant of the several reaction and transformation mechanisms which impact movement and fate of these compounds. Therefore, sorption processes must be made for accurate analysis of the contaminant transport, reliable assessment of risk and for selection and design of appropriate remedial measures (Krauss, 2005). Sorption is a physical and chemical process by which one substance becomes attached to another. The term "sorption" is used in the present context to describe any accumulation of dissolved substances by solid particles.

Amongst all phenomena governing sorption of substances in aqueous porous media and aquatic environments, the transfer of substances from a mobile phase (liquid or gaseous) to a solid phase is a universal phenomenon. The "isotherm", a curve describing the retention of a substance on a solid at various concentrations, is a major tool to describe and predict the mobility of this substance in the environment. These retention/release phenomena are sometimes strongly kinetically controlled, so that time-dependence of the sorption isotherm must be specified (Limousin et al., 2006). The ability of sediment-bound contaminants to partition or desorb to a mobile phase or the extractability of sediment bound contaminants using a solvent or a sorbent defines physical availability of contaminants. The biological availability describes the exposure, uptake and ultimate risk of sediment-bound contaminants to receptor organisms and biodegradation of sediment bound contaminants by microorganisms. To a great degree, physical availability of sediment-bound contaminants controls its bioavailability because the partitioning of a contaminant between the solid and water phases is a key indicator of the potential for exposure and risk (Pignatello, 2001). Thus, sorption and desorption of HOCs in natural sorbents are critical processes determining the transport, fate and bioavailability of HOCs in the environment although enormous uncertainty is involved in the quantification of the risk assessment. In naturally occurring systems most hydrophobic organic contaminants are associated with sediment or soil, sorbed primarily to the sediment/soil organic matter. Sorption and desorption of HOCs affect 
contaminant fate, toxicology and the efficiency of most remediation technologies. Characterization of the sorptive partitioning of a contaminant between soil and groundwater phases requires description of the nature of equilibrium conditions ultimately attained as well as the rates at which these conditions are approached. It has in the past been common for purposes of modeling simplification to assume that sorptive partitioning water can be represented by an isotherm which is approached rapidly enough to permit the further assumption of local equilibrium (Girvin, 1997). The relationship; $Q=f(C)$ is named "sorption isotherm".

This relationship requires several conditions to be met: (i) The various reaction equilibria of retention/release must have been reached and (ii) All other physico-chemical parameters are constant. The word "isotherm" was chosen because of temperature influence on sorption reactions; temperature must be kept constant and specified.

\section{Modeling}

Modeling is a scientific activity which makes a particular part or feature of the world easier to understand, define, quantify, visualize or simulate by referencing it to existing and usually commonly accepted knowledge. It requires selecting and identifying relevant aspects of a situation in the real world and then using different types of models for different aims, such as conceptual models to better understand, operational models to operationalize, mathematical models to quantify, and graphical models to visualize the subject. Modeling is an essential and inseparable part of many scientific disciplines, each of which has their own ideas about specific types of modeling.

\section{Absorption versus Adsorption}

\section{Absorption}

Absorption is a physical or chemical phenomenon or a process in which atoms, molecules or ions enter some bulk phase - gas, liquid or solid material. The absorbent distributes the material it captures throughout the whole system. In technology, chemical absorption is used in place of the physical process, e.g., absorption of carbon dioxide by sodium hydroxide such acid-base processes do not follow the Nernst partition law. If absorption is a physical process not accompanied by any other physical or chemical process, it usually follows the Nernst distribution law. Absorption is a process that may be chemical (reactive) or physical (nonreactive). Chemical absorption or reactive absorption is a chemical reaction between the absorbed and the absorbing substances. Sometimes it combines with physical absorption. This type of absorption depends upon the stoichiometry of the reaction and the concentration of its reactants (Schwarzenbach, 2003; Yang et al., 1998).

\section{Adsorption}

Adsorption is a surface phenomenon, which arises due to interactions between the individual atoms, ions or molecules of an adsorbate and those present in the adsorbent surface. Adsorption in the case of gas or liquid, solute accumulates on the surface of a solid or a liquid (adsorbent), forming a molecular or atomic film (the adsorbate). It is operative in most natural physical, biological, and chemical systems, and is having a large number of industrial applications. The process is accompanied by separation of the solute from one phase to another following its accumulation at2the adsorbent. Tien (1994) provided description of 
models and calculation procedures for the design 15and analysis of separation by physical adsorption. The biological carbon adsorption, adsorption with impregnated adsorbents, thermodynamics, adsorption equilibria, adsorption rate phenomena, theories of multi component systems, etc. were thoroughly reviewed. Sircar (1994) explained the role of adsorption technology as a key separation technique for the process industries. The pressure and vacuum swing adsorption are described with particular references to air separation for oxygen and nitrogen production. The recent theoretical and practical results achieved in gassolid, liquid-solid and gas-liquid adsorption research has been reviewed in a volume edited by Stumm et al (1980). The authors have given emphasis on the interpretation and application of different phenomena like adsorption on heterogeneous surfaces, adsorption from electrolyte solutions, polymer adsorption at solid surfaces, protein adsorption kinetics, principles and models of multi component adsorption, irreversible adsorption of particles, surface complexation models of adsorption, etc. Several reviews have appeared on water treatment through adsorption during the last few years. Jiuhui (2008) reviewed the use of adsorbents in structures, functions and characteristics. Gupta et al., (2009), prepared a low cost adsorbent from commercial waste materials (e.g., silica gel, zeolite, activated alumina, activated carbon), agricultural waste (e.g., rice and wheat waste, tea and coffee waste, coconut waste, peanut waste, vegetable/fruit peel, etc), and industrial waste (fly ash, blast furnace slag and sludge, red mud, etc). Adsorption here involves the accumulation of matter at the solid-water interface and is the basis of most surface-chemical processes.

i. It influences the distribution of substances between the aqueous phase and particulate matter, which, in turn, affects their transport through the various reservoirs of the earth. The affinity of the solutes to the surfaces of the "conveyor belt" of the settling inorganic and biotic particles in the ocean (and in lakes) regulates their (relative) residence time, their residual concentrations and their ultimate fate.

ii. Adsorption affects speciation of aquatic constituents. sorption affects the electrostatic properties of suspended particles and colloids, which, in turn, influences their tendency to aggregate and attach (coagulation, settling, filtration).

iii. Adsorption influences the reactivity of surfaces and interferes with the rates of precipitation (heterogeneous nucleation and surface precipitation), dissolution of minerals (of importance in the weathering of rocks and in the corrosion of structures and metals), and in the catalysis and photocatalysis of redox processes, are critically dependent on the properties of the surfaces (surface species and their structural identity).

Atoms, molecules and ions exert forces upon each other at the interface. Adsorption reactions are discussed primarily in terms of intermolecular interactions between solute and solid phases. This includes: Surface complexation reactions, the electric interactions, hydrophobic expulsion (hydrophobic substances) - this includes non polar organic solutes - which are usually only sparingly soluble in water, tend to reduce the contact in water and seek relatively non-polar environments and thus may accumulate at solid surfaces and may become absorbed on organic sorbents, Adsorption of surfactants (molecules that contain a hydrophobic moiety). (interfacial tension and substances intimately related through the Gibbs adsorption law; its main message - expressed in a simple way is that substances that tend to reduce surface tension, tend to become adsorbed at interfaces) and Polymers and of polyelectrolytes - above all humic substances and proteins is a rather general phenomenon in natural waters 
and soil systems that has far-reaching consequence on particles interaction with each other and on the attachment of colloids (bacteria) to surfaces.

\section{Types of Adsorption}

Depending upon the nature of force existing between adsorbate molecule and adsorbent, four types of adsorption can be distinguished.

(i) Physical adsorption or Physisorption results from the action of weak intermolecular forces. These are London dispersion forces and classical electrostatic forces that are related with interactions between the dipole moments of the molecules. It is nonspecific, i.e. the adsorbent does not have preference for any particular gas.

(ii) Chemical or Chemisorption adsorption involves strong adsorbate-adsorbent interactions resulting in a change in the chemical form of the adsorbate.

(iii) Exchange adsorption or ion exchange: This involves electrostatic attachment of ionic species to sites of opposite charge with subsequent displacement of these species by other ionic adsorbates of greater electrostatic affinity. In this adsorption, the characteristic interactions are ion-ion and ion-dipole types.

(iv) Specific adsorption: Attachment of adsorbate molecules at functional groups on an adsorbent surface can also result from specific interactions, which do not result in adsorbate transformation. These interactions exhibit binding energies from values associated with physical higher energies involved in chemisorption. The net dispersion, electrostatic, chemisorptive, and functional group interactions broadly define the ability of an adsorbent for a specific adsorption (Delle, 2001).

\section{Factors influencing adsorption}

(i) Adsorbent: The adsorbent must have good mechanical properties such as strength and resistance to attrition and it must have good kinetic properties, that is, its transferring adsorbing molecules rapidly to the adsorption solvent and the distribution of area with respect to pore size are two very important factors in determining extent and intra particle surface area markedly influences the types of adsorption process.

(ii) Characteristics which relate to certain properties relative to the solution phase, namely surface tension and solubility. The extent of adsorption is affected by solvophobicity or lyophobic.

(iii) Solution: aqueous phase, hydrogen ions and hydroxide ions often interact with adsorbents thus, the adsorption process may be affected by solution $\mathrm{pH}$. The temperature can also remarkably influence the adsorption process. Increase in temperature (for an endothermic) due primarily to the increased rate of diffusion of adsorbate molecules through the solution to the adsorbent. Temperature affects solubility which in turn affects adsorption thereby influencing competing adsorbate molecules. Few adsorbents demonstrate controllable selectivity for specific adsorbates and thus, all adsorbable compounds present will compete for adsorption sites. 


\section{Reversibility of Adsorption}

This establishes an adsorption equilibrium, thus desorption has received relatively little experimental attention. If adsorption of bimolecular reactions is suggested by the Langmuir equation.

$$
\begin{aligned}
& S+A=S A \\
& \mathrm{~kb} \text { can be postulate as } \frac{d[S A]}{d t}=k f[S][A]-k b[S A] \\
& \text { and at equilibrium, } \frac{d[S A]}{d t}=0, \frac{[S A]}{[S][A]}=\frac{k f}{k b}=K=K a d s
\end{aligned}
$$

If one of the kinetic constants and Kads is known, the other rate constant can be calculated.

\section{SORPTION OF ORGANIC COMPOUNDS TO INORGANIC SURFACES}

The sorption of hydrophobic substances in the environment is dominated by organic matter $(\mathrm{OM})$ and dependent on the amount of the soil organic matter in a given sorbent (Clark et al., 2010). However, for solids containing no or low contents of OM (as a rule of thumb less than $0.1 \%(\mathrm{w} / \mathrm{w}))$, sorption to mineral surfaces becomes the dominant process. Huang et al (1996) reported numerous investigations on HOCs showing significant sorption to mineral surfaces in aqueous solutions. In environmental chemistry and analysis, inorganic surfaces, in particular untreated (uncoated) glass surfaces, are important if the concentrations of compounds under investigation are small. Although numerous investigations that focused on the study of HOCs have reported a significant loss of analyte that was subscribed to adsorption to the walls of glass vials (Xia et al., 2001), in most reports this process was merely held responsible for observed mass losses without a detailed investigation. A systematic investigation of sorption to inorganic surfaces, especially to untreated glass surface, and developing a predictive method that enables a-prior decisions if in critical or not, are important issues from the practical side.

\section{The "Sorption" of Hydrophobic Substances}

The lipophilicity compounds have the tendency to become dissolved in a lipid, and are often measured by their tendency to dissolve in nonpolar solvent, for example, by the n-octanolwater distribution coefficient. The lipophilicity of a substance is inversely proportional to its water solubility (Huang, 2003). Synthetic chemicals which are now receiving more attention from researchers due to the health risks posed to the environment with a pool of information available in literature on the behaviour. Anthropogenic generated pollutants are widely distributed and of large concern. Trichloroethylene: Trichloroethylene (TCE) is a halogenated, aliphatic organic compound. TCE is a colourless liquid with a slightly sweet smell. TCE is used in metal degreasing, textile cleaning, solvent extraction processes and carrier solvent (Benjamin, 2002). In recent years, industries have grown extremely, exposing groundwater and aquifers to intense risks of being polluted with TCE. This compound unpredictably contaminates the environment. It undergoes many processes inclusive adsorption onto soils, volatilization, desorption and transformation. Partitioning of TCE from surface waters to air is quick with a half-life of numerous days to several weeks. Evaporation 
is the main process of elimination of TCE from surface waters while photo oxidation, hydrolysis and biodegradation play a minor role. The conditions might be different in groundwater, where TCE may be biotransformed under appropriate anaerobic conditions into dichloroethylene, chloroethane and vinyl chloride with a biodegradation half-life ranging from several months to several years. The volatilization of the atmosphere is also the main process of elimination of TCE from the soil. The process is comparatively fast but slower than from surface waters. Under anaerobic conditions TCE may bio-transfer to vinyl chloride which is far more toxic than TCE. In many areas vinyl chloride was used on site, signifying that this transformation is happening. Danger management activities need to address not only the danger posed by TCE itself but also TCE as a precursor of vinyl chloride. (Kalinovich et $a l ., 2012$ ). The movement of TCE in soil is principally affected by the organic carbon content (OC) which affects sorption to the soil. Experimentally calculated sorption coefficients (Koc) for TCE in soils are ranging from 106 - 460. TCE density is greater than water and it tends to settle at the aquifer base. From these pools, TCE may be slowly released over a long time. The indications of exposure to TCE are manifested as central nervous system problems. They include headache, drowsiness, hyperhidrosis and tachycardia. In more severe cases coma may result. Psychomotor impairment was observed after inhalation when exposed to 5,400 $\mathrm{mg} / \mathrm{m} 3$ for two hours in work place conditions. TCE vapours can also be the reason for eye irritation. High oral doses can be toxic to the liver and kidneys. The Environmental Protection Agency (EPA) defined a maximum contaminant level $5 \mathrm{~g} / \mathrm{L}$ of trichloroethylene (TCE) for drinking water. TCE is quickly absorbed as soon as it is inhaled; 37-64\% of the inhaled TCE can be taken up in the lungs. Once TCE is in the body it is distributed and accumulates in tissue. TCE exits the body unchanged in exhaling air and to a lesser degree in feces. TCE, however, may be rapidly metabolized in the liver (Ren, 2002). Tetrachloroethylene: Tetrachloroethylene (PCE, perchloroethylene) is one of the five most often identified volatile organic compounds found in municipal groundwater supplies. Tetrachloroethylene is a manufactured chemical that is extensively used in the dry-cleaning of textiles. Other names for Tetrachloroethylene include PERC, perchloroethylene, Tetrachloroethylene and PCE. Microbial degradation of PCE does primarily occur anaerobically by reductive dehalogenation to less chlorinated ethylenes trichloroethylene (TCE), dichloroethylene (DCE), vinyl chloride (VC) and ethylene as well as to ethane. Vinyl chloride which is carcinogenic to humans and both is considered US EPA priority pollutants. Similarly to TCE, DCE mobility depends on physical processes like volatilization and sinking due the effect of gravity as well as degradation processes.

Xylene: Xylene is an aromatic hydrocarbon with two methyl groups attached. Three isomers exist: $\mathrm{p}$-xylene, $\mathrm{o}-x y l e n e$, and $\mathrm{m}$-xylene. The extreme complexity in separating these isomers has led to one of the most interesting subjects in the oil industry because extraction is only possible for removing o-xylene but fails in the other two isomers because of the similarity of their boiling points. Temporarily, these isomers are very poisonous volatile organic compounds (VOCs) and failure in separating them from the industrial discharges results in the release of the mixture during attempts to separate xylene isomers. The earliest effects of exposure to xylene are increased liver enzymes. Other effects of a single or short time exposure include irritation of nose, eyes, and throat, headache, nausea, dizziness, vomiting, fatigue, light-headedness, irritability, loss of appetite, reduced coordination, abdominal pain and loss of consciousness (Hu et al., 2011). 


\section{Sorption of hydrophobic organic compounds in soils and sediments}

This occurs generally in soil organic matter (Karikhoff et al., 1979; Grathwohl, 1989). Based on this observation, the KOC concept was developed that relates these compounds to sorption to specific organic carbon (OC) fraction. With this, the distribution coefficient $\mathrm{KOM}(1 / \mathrm{kg})$ can be defined:

$$
K O M=C O M / C W
$$

and the more specific $\mathrm{KOC}(1 / \mathrm{kg}): \mathrm{KOC}=\mathrm{COC} / \mathrm{CW}=\mathrm{KOM} / \mathrm{fOC}=\mathrm{KOM} / 0.58$

where COM $(\mathrm{mg} / \mathrm{kg})$ is the concentration of the compound in the organic matter, $\mathrm{COC}(\mathrm{mg} / \mathrm{kg})$ the concentration of the compound in organic carbon, and fOC (-) is the fraction of organic carbon in the soil or sediment. The factor 0.58 accounts for the fact that on average $58 \%$ of the organic matter consists of organic carbon. KOC values are helpful in predicting transport behavior of organic pollutants in soil. Higher KOC values are associated with less mobile organic compounds while lower KOC values are associated with more mobile organic substances. Kd and $\mathrm{KOC}$ are related to each other with the following equation:

$$
K d=K O C / f O C
$$

As a further simplification it was found that a very good correlation exists between the KOC and the octanol/water coefficient (KOW) of a hydrophobic compound, indicating that octanol is a very good analogous to organic matter. KOW values for numerous organic compounds are tabulated or can be calculated. Based on experimental results KOW-KOC relationships were developed as an analogous to linear free energy relationships (Karikhoff et al., 1979; Karikhoff, 1981; Chiou et al.. 1979):

$$
\log K o c=\operatorname{alog} K o w
$$

and the necessary parameters $a$ and $b$ were determined. The KOW values can then be used to calculate the respective $\mathrm{KOC}$ values.

\section{The "Sorption" of Hydrophobic Substances to Solid Materials that contain Organic Carbon}

The attachment of non-polar hydrophobic substances to solid material that contain organic carbon must be interpreted as "absorption", i.e., a "dissolution" of the hydrophobic compound into the bulk material usually present as a component adsorbent. The uptake of such a hydrophobic substance may be compared with the partitioning of a solute between two solvents - liquid and solid phase. The partition coefficient Kp (similar to a distribution coefficient) is defined as:

$$
\mathrm{K}_{\mathrm{p}}=\frac{\mathrm{mol} \text { sorbate / mass of solid }}{\mathrm{mol} \text { of solute / volume of solution }}\left[\frac{e}{\mathrm{~kg}}\right] \text { or }\left[\frac{10^{-3} \mathrm{~m}^{3}}{\mathrm{~kg}}\right]
$$

The absorption increases with the content of the organic material in the solid phase and the hydrophobicity of the solute. Thus, $\mathrm{Kp}$ is empirically found to correlate with the organic 
carbon content of the solid phase, foe (weight fraction) and the hydrophobicity of the solute Know. The tendency of the compound to be absorbed (to dissolve) in the organic phase is related to the dissolution of the compound in n-octanol, i.e., to the chemical's octanol-water partition coefficient.

$$
\text { Kow }=\frac{[\text { Aoct }]}{[\text { Aaq }]}
$$

Thus, the partition coefficient for the (ab)sorption of an organic solute onto a solid phase is given by (Schwarzenbach and Westall, 1981).

$$
\mathrm{K}_{\mathrm{P}}=\mathrm{bf}_{\mathrm{oc}}\left(\mathrm{K}_{\mathrm{ow}}\right) \mathrm{a}
$$

where $\mathrm{a}$ and $\mathrm{b}$ are constants. $\mathrm{a}$ is often around 0.8 . Increasing water solubility corresponds to decreasing partitioning into the solid phase. The effect that hydrophobic organic substances can become sorbed to organic coatings can be used to make sorbents by coating inorganic colloids such as ferrihydrite with surfactants. Such surfactant-coated surfaces contain films of chemicals which are able to remove hydrophobic solutes, such as toluene or chlorohydrocarbons, from solution ( Tandlich, 2004).

\section{DIFFERENT MODELS FOR HYDROPHOBIC CONTAMINANTS 1}

The simplified representation of reality considering only the characteristics of substances in a system are important to the problem at hand. A model is a description of data without theoretical basis. A chemical model provides an inside into a chemical system consistent with its chemical properties and it is simultaneously as simple and as chemically correct as possible. The ideal model is effective, comprehensive, realistic and predictive (Barrow and Bowden, 1981) and applied to different conditions. Unlike empirical models, surface complexation models are chemical models that strive to satisfy the above characteristics and to give a general molecular description of adsorption phenomena using an equilibrium approach. Molecular theory derived the thermodynamic properties of the activity coefficient and equilibrium constants from the principles of statistical mechanics (Sposito, 1981). The surface complexation model is designed to calculate values for the thermodynamic properties mathematically and constitute a family of models having similar characteristics. This family models include the constant capacitance model (Stumm et al, 1980), the triple-layer model, (Devis et al, 1978), the Stern variable surface charge - variable charge surface potential model (Bowden et al, 1981), the generalized two - layer model (Dzombak and Morel, 1990) and the one - pK model (van Riemsdijk et al., 1986). The major advancement in the surface complexation model is that they consider surface charge. Surface charge results from protonation and dissociation reaction as well as from surface complexation reactions of reactive surface hydroxyl groups on mineral surfaces with charge dependent on the $\mathrm{pH}$ and electrolyte solution.

\section{Empirical Models}

A generalized empirical adsorption isotherm equation can be written as

$$
\mathrm{X}=\mathrm{bK}_{\mathrm{C}}^{\beta} / 1+\mathrm{K}_{\mathrm{C}}^{\beta}
$$


where $\mathrm{x}$ is the amount adsorbed per unit mass; $\mathrm{c}$ is the equilibrium solution concentration; and $b, K$, and $\beta$ are empirical parameters. The distribution coefficient, $K$, is a linear equilibrium adsorption isotherm

$$
\mathrm{X}=\mathrm{Kdc}
$$

Adsorption data usually conform to the linear assumption of the distribution coefficient expression over a very restricted solution concentration range. 6The distribution coefficient is a special case of Eq. [10] where $b=\beta=1$ and $K, c<<1$.

\section{Chemical Models}

As their name implies, surface complexation models treat ion adsorption as complexation reactions analogous to complex formation in solution. These complexes are strong complexes involving either ionic or covalent bonding (Ding et al., 2006). Outer-sphere surface complexes contain at least one water molecule between the adsorbing ion and the surface functional group. These complexes involve electrostatic bonding and are less stable than inner-sphere surface complexes. Surface complexation models consider the charge of both the adsorbate ion and adsorbent surface. This can be considered their most significant advancement over the empirical models. The models differ in their structural representation of the solid-solution interface, that is, the location and hydration status of the adsorbed ions. 4

\section{Constant Capacitance Model}

The constant capacitance model of the oxide-solution interface was developed by Schindler, Stumm, and their co-workers. The assumptions in the constant capacitance model are:

(i). All surface complexes are inner-sphere complexes.

(ii). The constant ionic medium reference state determines the activity of the aqueous species and therefore no surface complexes are formed with ions from the background electrolyte.

(iii). one plane of charge represents the surface

(iv). The relationship between surface charge density, 0 , and surface potential. (where 0 represents the surface plane), is where $\mathrm{C}$ is the capacitance density $\left(\mathrm{F} \mathrm{m}^{-1}\right), \mathrm{S}$ is the surface area $\left(\mathrm{m}^{2} \mathrm{~g}^{-1}\right)$, a is the suspension density $\left(\mathrm{g} \mathrm{l}^{-1}\right), \mathrm{F}$ is the Faraday constant $(\mathrm{C}$ $\left.\mathrm{mol}^{-1}\right)$, cr has units of molt $\mathrm{l}^{-1}$ and $\mathrm{uj}$, has units of $\mathrm{V}$. The equations for the surface complexation reactions 4(Hohl et al., 1981).

$$
\begin{aligned}
& \mathrm{XOH}+\mathrm{H}^{+} \leftrightarrow \mathrm{XOH}_{2} \\
& \mathrm{XOH} \leftrightarrow \mathrm{XO}^{-}+\mathrm{H}^{+} \\
& \mathrm{XOM}+M^{m+} \leftrightarrow \mathrm{XOM}^{(m-1)}+H^{+} \\
& 2 \mathrm{XOH}+M^{m+} \leftrightarrow(X O)_{2} M^{(m-2}+2 H^{+} \\
& \mathrm{XOH}+L^{l-} \leftrightarrow X^{l-1}+O H^{-} \\
& 2 \mathrm{XOH}+L^{l-} \leftrightarrow X_{2} L^{(l-2)}+2 \mathrm{OH}^{-}
\end{aligned}
$$


$\mathrm{XOH}$ represents the surface functional group, $\mathrm{M}$ is a metal ion of charge $\mathrm{m}+$, and $\mathrm{L}$ is a ligand of charge 1 . The intrinsic conditions equilibrium constants describing the surface complexation reactions are

$$
\begin{aligned}
& K+(\text { int })=\frac{\left[\mathrm{XO}^{-} \mathrm{H}_{2}^{+}\right]}{[\mathrm{XOH}]\left[\mathrm{H}^{+}\right.} \exp [F \Psi O / R T] \\
& K-(\text { int })=\frac{\left.X O^{-}\right]\left[H^{+}\right]}{[X O H]} \exp [F \Psi O / R T] \\
& K_{M}^{l}(\text { int })=\frac{\left[X O M^{(m-1)}\right]\left[H^{+}\right]}{[X O H]\left[M^{m+}\right]} \exp [(m-1) F \Psi O / R T] \\
& K_{M}^{2}(\text { int })=\frac{\left[(X O)_{2} M^{(m-2)}\right]\left[H^{+}\right]^{2}}{[X O H]\left[M^{m+}\right]} \exp [(m-2) F \Psi O / R T] \\
& K_{L}^{l} \text { (int) }=\frac{\left[X L^{(l-1)-}\right]\left[O H^{-}\right]}{[X O H]\left[L^{l-}\right]} \exp [-(l-1) F \Psi O / R T] \\
& K_{L}^{2} \text { (int) }=\frac{\left[X_{2} L^{(l-2)-}\right]\left[O H^{-}\right]}{[X O H]\left[L^{l-}\right]} \exp [-(l-2) F \Psi O / R T]
\end{aligned}
$$

(18) (19) (20) (21) (22) (23) where R is the molar gas constant (J mol-1 K-1), int represents intrinsic, $\mathrm{T}$ is the absolute temperature $(\mathrm{K})$, and square brackets represent concentrations (mol L-1). The expression for the surface functional group, XOH, (Sigg and Stumm, 1981) is:

$$
\begin{aligned}
& {[X O H]=[X O H]+\left[X_{2}^{+}\right]+\left[X O^{-}\right]+\left[X O M^{(m-l)}\right]} \\
& +2\left[(X O)_{2} M^{m-2}\right]+\left[X L^{L-1}\right]+2\left[X_{2} L^{(L-2)}\right]
\end{aligned}
$$

The charge balance express is (Sigg and Stumm, 1981).

$$
\begin{aligned}
& \sigma=\left[X O H_{2}^{+}\right]-\left[X O^{-}\right]+(m-1)\left[X O M^{m-1}\right]+(m-2)\left[(X O){ }_{2} M^{(m-2)}\right] \\
& -1(l-1)\left[X L^{(L-1}\right]-(l-2)\left[X_{2} L^{(l-2)}\right]
\end{aligned}
$$

The constant capacitance model resembles the Helmholtz double layer in that the adsorbing ions are located immediately adjacent to the surface. 


\section{Diffuse Layer Model}

The diffuse layer model of the oxide-solution interface was proposed by Stumm and coworkers and developed as the generalized two-layer model. The assumptions in the diffuse layer model are: All surface complexes are inner sphere complexes, no surface complexes are formed with ions in the background electrolyte, two planes of charge represent the surface and the relationships between surface charges and surface potentials.

$$
\Psi_{O}=\Psi_{d}
$$

$$
\sigma_{d}=-\frac{S a}{F} \operatorname{sgn} \Psi_{d}\left\{2 \in_{o} D R T \sum_{i} C i\left[\exp \left(-z_{i} F \Psi_{d} / R T\right)-1\right)\right\}^{1 / 2}
$$

where $\mathrm{E}$, is the permittivity of vacuum, $\boldsymbol{D}$ is the dielectric constant of water, $\mathrm{I}$ is the ionic strength, $\operatorname{sgn} \Psi_{d}=1$ if $\Psi_{d>0}$ and $\operatorname{sgn} \Psi_{d}=-1$ if $\Psi_{d<0}$ (where $d$ represents the diffuse plane), and $\mathrm{Ci}$ and $\mathrm{Zi}$ are the concentration and charge of solution Species i. Equation [26] is equivalent to the Gouy-Chapman equation and applies to symmetrical electrolytes while Eq. [27] represents the general case. The equations for the surface complexation reactions are Eq. [26] and [27] for protonation-dissociation and Eq. [28] for metal adsorption. In the generalized two layer model no bidentate surface complexes are defined. The equations for the ligand surface complexation reactions. The equations for the ligand 18 surface complexation reactions are:

$$
\begin{aligned}
& X O H+L^{l-}+H^{+} \Leftrightarrow X L^{(L-1)}+H_{2} O \\
& X O H+L^{l-}+2 H^{+} \Leftrightarrow X H L^{(L-2)-}+H_{2} O
\end{aligned}
$$

The intrinsic conditional equilibrium constants for the surface complexation reactions are Eq. [29] and [30] for protonation-dissociation and Eq. [30] for metal adsorption. The intrinsic conditional equilibrium constants describing the ligand surface complexation reactions are (Hayes et al., 1991).

$$
K_{L}^{1}(\text { int })=\frac{\left[X L^{(L-1)}\right]}{[X O H]\left[L^{l-}\right]\left[H^{+}\right]} \exp \left[-(l-1) F \Psi_{d} / R T\right.
$$




\section{Triple Layer Model}

This is an extension of the site binding model and modified to include inner-sphere surface complexation. The assumptions of the triple layer model are: (i) Protons and hydroxyl ions form inner-sphere surface complexes. (ii) Ion adsorption reactions form either outersphere or inner-sphere surface complexes. 4(iii) Complexes are formed with ions from the background electrolyte (iv). The three charges represent the surface. (v) The relationships of surface charges and surface potentials are shown in Eq. [32] and [33].

$$
\begin{gathered}
\sigma_{O}=\frac{C_{1} S A}{F}\left(\Psi_{O}-\Psi_{\beta}\right) \\
\sigma_{d}=\frac{C_{2} S a}{F}\left(\Psi d-\Psi_{\beta}\right)
\end{gathered}
$$

(32) (33) where $\mathrm{C}_{1}$ and $\mathrm{C}_{2}$ are capacitance densities.

The equations for the outer- sphere surface complexation reactions are; (34) (35)

$$
\begin{aligned}
& X O H-M^{m+} \Leftrightarrow X O^{-}-M^{m+}+H^{+} \\
& X O H-M^{m+} H_{2} O \Leftrightarrow X O^{-}-M^{(m-1)}+2 H^{+}
\end{aligned}
$$

\section{Mass transfer models}

These models are important for estimation of transport coefficients from kinetic curves and also as basic constituents of fixed-bed adsorber models, prior to the presentation of the different kinetic approaches. Generally, the model includes mass transfer equations, equilibrium relationships, and the material balance for the reactor applied. With the common assumptions that the temperature is constant, the bulk solution completely mixed, the mass transfer into and within the adsorbent can be described as diffusion processes, the attachment lof the adsorbate onto the adsorbent surface is much faster than the diffusion processes, the adsorbent being spherical and isotropic.

Most importantly, adsorption kinetics is not independent of adsorption equilibrium. Therefore, the models can be applied only if the required equilibrium parameters are known. A widely used simplification in view of multicomponent adsorption consists of the competition influences in only the equilibrium. Consequently, the mass transfer equations for single-solute and multi-solute adsorption are the same, and the kinetic models for single solute and multi-solute adsorption differ only in the description of the equilibrium. Furthermore, the mass transfer coefficients can be determined in single-solute experiments 
because the coefficients for single-solute and multi-solute adsorption are assumed to be identical. The differential material balance for a batch system reads.

$$
m_{A} \frac{d q}{d t}=-V_{L} \frac{d c}{d t}
$$

Where $\mathrm{m}_{\mathrm{A}}$ is the adsorbent mass and $\mathrm{V}_{\mathrm{L}}$ is the liquid volume in the reactor. This equation links the change of the mean adsorbent loading with time to the change of the liquid-phase concentration with time. Integration of Equation [36] with the initial conditions

$\mathrm{c}(\mathrm{t}=0)=\mathrm{c} 0$ and $\mathrm{q}(\mathrm{t}=0)=0$ leads to the material balance equation in the form (Bar-Tal, 1990).

$$
\bar{q}(t)=\frac{V_{L}}{m_{A}}\left[c_{0}-c(t)\right]
$$

The kinetic models often use dimensionless quantities.

After introducing the distribution parameter for the batch reactor, $\mathrm{D}_{\mathrm{B}}$,

$$
D_{B}=\frac{m_{A} q_{0}}{V_{L} c_{0}}
$$

and the dimensionless concentration and adsorbent loading is given as

$$
X=\frac{c}{c_{0}}, \bar{Y}=\frac{q}{q_{0}}
$$

the dimensionless material balance equation can be expressed as

$$
X+D_{B} \bar{Y}=1
$$

The loading, $\mathrm{q}_{0}$, is the equilibrium adsorbent loading related to the initial concentration, $\mathrm{c}_{0}$.

\section{SORPTION ISOTHERMS AND SORPTION COEFFICIENT}

The standard characterization of an HOC's sorption behaviour is via the corresponding sorption isotherm. generally speaking, all these models are related to dissolved sorbate concentration $\mathrm{C}_{\mathrm{a}}$ (unit $\mu \mathrm{g} / \mathrm{mL}$ or $\mathrm{mg} / \mathrm{L}$ ) and the sorbed concentration of the sorbate $\mathrm{q}_{\mathrm{e}}$ (unit $\mathrm{mg} / \mathrm{kg}$ dry weight of soil sorbent or $\mu \mathrm{g} / \mathrm{mg}$ dry weight of soil sorbent; and the molar version has the unit of $\mathrm{mmol} / \mathrm{g}$ or $\mathrm{mmol} / \mathrm{kg}$ ). The Different models have provided an insight into the sorption mechanism of a given HOC onto a particular soil/clay mineral which in turn allows 
making predictions about the environmental concentrations of contaminants and the the implications of environmental management. The following sections provide an outline of 12the most common models that have been applied to sorption of the HOCs in soils.

\section{The Langmuir isotherm}

The Langmuir model (Langmuir, 1918) is a non-linear isotherm based on the assumption that adsorption energy is constant and independent of surface coverage. The adsorption takes place on localized sites with no lateral adsorbate-adsorbate interactions. Langmuir model was derived from mass action, kinetic, or statistical thermodynamic approaches considering the valid assumptions that the adsorption of a single adsorbate onto a series of equivalent sites on the surface of the solid is perfect, adsorbing gas absorbs into an immobile state, all sites are equivalent and each site can hold at most one molecule in there are no interactions between adsorbate molecules on adjacent sites

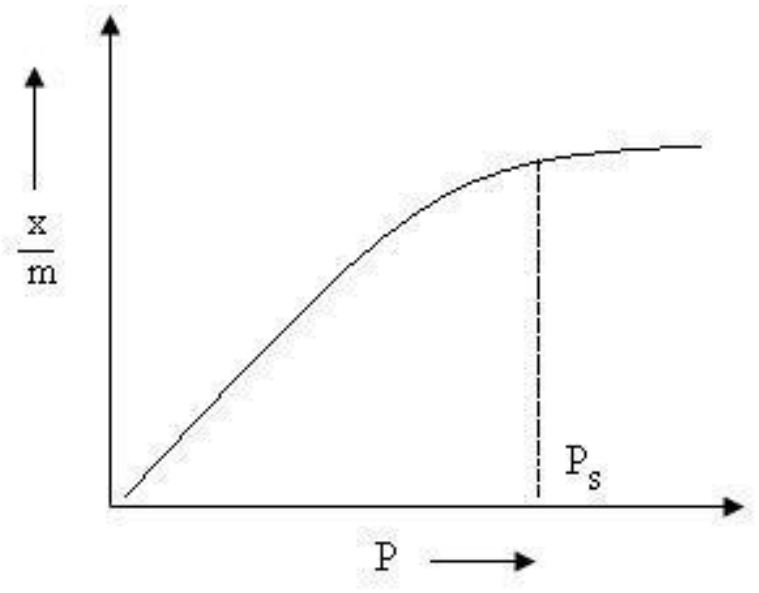

\section{Figure 1.Type I Adsorption Isotherm}

The concept of the theory is an extension theory, in which gas molecules only interact with adjacent layers and the Langmuir theory can be applied to each layer. The rate at which adsorbate molecules strike a surface of an adsorbent is proportional to the output of the solute concentration $(\mathrm{C})$ and the fraction (1- q) remaining uncovered by adsorbate and therefore available as adsorption sites. The sorption from the surface is directly proportional to the fractional surface coverage, $\mathrm{q}$, and the rates of adsorption and desorption are equal at equilibrium. Thus,

$$
k_{a}=C(1-\theta)=k_{d} . \theta
$$

where $\mathrm{k}_{\mathrm{a}}$ and $\mathrm{k}_{\mathrm{d}}$ are the rate coefficients for sorption. The fractional surface coverage, $\mathrm{q}$, is then,

$$
\theta=q_{e} / q_{m}=b C_{e} /\left(1+b C_{e}\right)
$$

where $\mathrm{b}$ is $\mathrm{k}_{\mathrm{a}} / \mathrm{k}_{\mathrm{d}}$ and $\mathrm{q}_{\mathrm{m}}$ is the quantity of adsorbate forming a single monolayer on unit mass and $\mathrm{q}_{\mathrm{e}}$ is the amount adsorbed on unit mass with the equilibrium concentration is $\mathrm{C}_{\mathrm{e}}$. The simple derivation assumes that a single molecule occupies a single surface site with no 
interactions between adjacent adsorbed molecules. The application of the kinetic theory of gases reveals that the constant $b$ can be identified as:

$$
1 / b=(v / \sigma)(2 \Pi m k T)^{1 / 2} \exp (-Q / R T)
$$

Where $\mathrm{Q}=$ the heat of adsorption, $v=$ the pre-exponential factor of the desorption rate coefficient $\mathrm{t}=$ the condensation coefficient of the adsorbate, $\mathrm{m}=$ mass and $\mathrm{k}=$ the Boltzmann constant. Equation (43) can be simplified to the form:

$$
q_{e}=\left(q_{m} b C_{e}\right) /\left(1+b C_{e}\right)
$$

or in the linear form as:

$$
C_{e} / q_{e}=\left(1 / b q_{m}\right)+/\left(1 / q_{m}\right) C_{e}
$$

The linear Langmuir plots are obtained by plotting $\mathrm{C}_{\mathrm{e}} / \mathrm{q}_{\mathrm{e}} \mathrm{vs}$. $\mathrm{C}_{\mathrm{e}}$. 68The slope and the intercept of this plot give the values of $\mathrm{q}_{\mathrm{m}}$ and $\mathrm{b}$. The Langmuir equation is also used to obtain RL, $\mathrm{a}$ dimensionless equilibrium parameter or the separation factor from the expression:

$$
R_{L}=1 /\left(1+b C_{e}\right)
$$

Where $\mathrm{C}_{\mathrm{e}}$ is any equilibrium liquid phase concentration of the solute at which adsorption is carried out. The isotherms are indicated by the $\mathrm{R}_{\mathrm{L}}$ value. The isotherm was first used to describe gaseous sorption onto solids and has been adopted to describe the sorption of chemical substances by natural solids Langmuir model (1918).

Brunauer-Emmett-Teller (BET) equation (Brunauer et al.,1938), is a model that

interprets multi-layer sorption isotherms, particularly the types II and III in (figure 2) and give an effective method for estimating the amount of bound water in specific polar sites of dehydrated solute systems (Sahin and Gülüm ,2006,), it express by the equation:

$$
M_{w}=\frac{M_{0} C a_{w}}{\left.\left.1+a_{w}\right)(1+C-1) a_{w}\right)}
$$

Where $\mathrm{M}_{0}$ is the monolayer moisture content, which represents the water attached to polar and ionic groups, $\mathrm{C}$ is energy constant of the first layer and the other remaining layers. These constants are also the constant characteristic of the isotherm of sorption of monolayer of Langmuir. In almost all cases, the deviation of the linearity of these graphs indicates that, at high vapour pressures, the amount adsorbed by the sorbent is lower than the one predicted by the isotherm (Sahin and Gülüm ,2006).

BET graphs are linear only in a limited range of water activity from 0.05 to 0.45 . The difficulty in the process of fitting the experimental data on the totality of the range of relative 
pressure application determined that the main application of the BET equation is the one related to the estimation of surface areas (Zung, 2002). 2The equation assumes that: the rate of condensation on the first layer is equal to the rate of evaporation from the second layer; the binding energy of all of the adsorbates on 30the first layer is same; and the binding energy of the other layers is equal to the one of pure adsorbates. (Blahovec and Yanniotis, 2009, Levine and Slade, 1991).

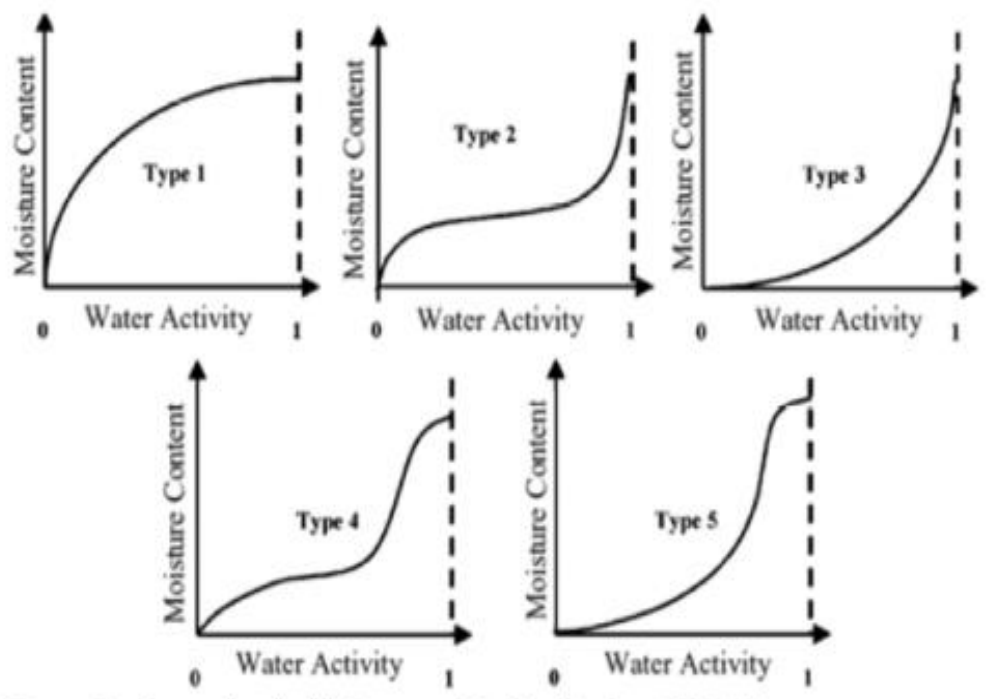

Figure 2. Types of isotherms described by Brunauer (Mathlouthi \& Roge, $2003(20)$ ).

\section{The Freundlich isotherm (Freundlich, 1906)}

The model is perhaps the most widely used non-linear adsorption equilibrium model which can be shown to be thermodynamically rigorous for adsorption on multiple surfaces of solid. It is used in cases where the identity of coloured solute material is not known,

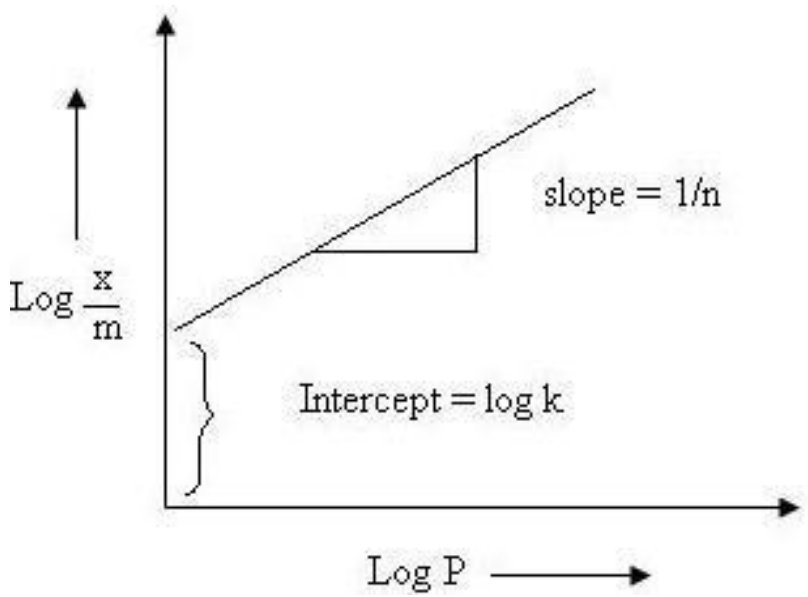

Figure 3. $\log (\mathbf{x} / \mathbf{m})$ vs. $\log p$ graph 
Beyond that point, the rate of adsorption saturates even after applying higher pressure. Thus, Freundlich adsorption isotherm failed at higher pressure. The isotherm has the expression:

$$
q_{e}=K_{F}+C_{e}^{1 / n}
$$

where $\mathrm{C}_{\mathrm{e}}$ and $\mathrm{q}_{\mathrm{e}}$ are the 1equilibrium concentrations of the solute in the liquid phase and in the solid phase respectively, $\mathrm{K}_{\mathrm{F}}$ and $\mathrm{n}$ being Freundlich coefficients, representing adsorption capacity and adsorption intensity respectively. For favorable adsorption, $\mathrm{n}$ is generally $<1$. The logarithmic equation below

$$
\log q_{e}=\log K_{F}+n \log C_{e}
$$

is more useful for fitting data from batch equilibrium studies. The values of $\mathrm{K}_{\mathrm{F}}$ and $\mathrm{n}$ are obtained from intercept and slope of the plots of $\log \mathrm{q}_{\mathrm{e}} \mathrm{vs} . \log \mathrm{C}_{\mathrm{e}}$ respectively. where $\mathrm{q}_{\mathrm{e}}$ and $\mathrm{C}_{\mathrm{e}}, 1, \mathrm{q}_{\mathrm{e}}$ is the amount adsorbed on unit mass with the equilibrium concentration is $\mathrm{C}_{\mathrm{e}}$.

\section{Isotherms of Uncharged Organic Compounds}

Excellent review about the adsorption and desorption mechanisms have been documented (Huang et al., 2003). Although sorption of uncharged solid organic matter predominates in most cases, $\mathrm{K}_{\mathrm{d}}$ is proportional to the mass in the solid $\mathrm{foc}_{\mathrm{oc}}\left(\mathrm{kg} \mathrm{kg}^{-1}\right)$ and to the affinity constant between 1the carbon material; $\mathrm{K}_{\mathrm{oc}}\left(\mathrm{L} \mathrm{kg}^{-1}\right)$. Moreover, Koc is often well correlated to the coefficient of the material between water and another organic substance (or even its constant of solubility) by a logarithmic relationship. (Eq. 48). Many times, the chosen partition easily available is octanol/water partition coefficient $\mathrm{K}_{\text {ow }}\left(\mathrm{L} \mathrm{kg}^{-1}\right)$. This relation was verified for a wide variety 8of solids and uncharged organic compounds (Schwarzenbach and Westall, 1981), or even for charged organic compounds for which the non-polar part is big enough. Though the parameters are dependent on the nature of the solid organic matter and on the class of adsorbed organic compounds, they are often found to remain constant for a wide range of soils and organic compounds. Thus, it becomes possible to give an estimation of adsorbed uncharged organic compounds at low concentration on any natural material with two easily measured parameters: the organic carbon content of the material and the octanol/water partition coefficient of the compound.

Gerstl, (1990) studied the effects of vegetative management, soil properties and highmolecular weight dissolved organic matter on the soil sorption of sulfamethazine. Three soils were sampled and tested within a dissolved concentration interval of $2.5-50 \mu \mathrm{mol} / \mathrm{L}$ of the antibiotic. The Freundlich isotherm model best described the sorption of sulfamethazine with Kf values ranging from 2.754 to $8.511(\mathrm{~mL} / \mathrm{g}) 0.59-0.79$ and the Freundlich exponent varying between 0.59 and 0.79 (Chu et al., 2013). The apparent soil/water partition coefficients indicated that vegetative management, the concentration of organic carbon, soil $\mathrm{pH}$ and the initial sulfamethazine concentration were the most important factors governing the soil sorption of the antibiotic (Chu et al., 2013). In clay soils, the sulfamethazine sorption was virtually independent of the soil $\mathrm{pH}$, and the same observation was made about the antibiotic sorption in all three soils with respect to dissolved organic matter (Ding et al., 2006). In the concentration range from $1 \mu \mathrm{g} / \mathrm{L}$ to $9 \mu \mathrm{g} / \mathrm{L}$, cypermethrin (a pesticide) followed the Freundlich isotherm and its affinity to mineral surfaces decreased in the following order: corundum > quartz > kaolinite > montmorillonite > goethite (Oudou et al., 2002). This pesticide can form diastereoisomers which follow linear sorption isotherms on quartz, 
corundum and goethite. The isotherms became non-linear for the cis $\mathrm{A}$ and trans $\mathrm{C}$ isomers on kaolinite and montmorillonite. Kaolinite proved to have the highest sorption affinity towards cis B and trans D isomers (Oudou et al., 2002). This supports the above conclusion about the possibility of applying kaolinite in remedial operations for the removal of aromatic hydrocarbons, their chlorinated derivatives and pesticides.

\section{The Linear Isotherm}

In linear isotherms, sorption of HOCs onto soils and clay minerals occurs due to partitioning and is described by the soil/water sorption partition coefficient for the respective sorbate, i.e., $K_{\mathrm{d}}$ (units $\mathrm{mL} / \mathrm{g}$ or $\mathrm{mmol} / \mathrm{g}$ ) (Limousin et $a l ., 2007$ ). Mathematically, $K_{\mathrm{d}}$ can be defined using Equation (49) as shown below:

$$
q_{e}=K_{d} \times C_{e}
$$

All terms in the equation have the same meaning as in Langmuir and Freundlich Isotherms and the unit of the linear sorption partition coefficient $\mathrm{K}_{\mathrm{d}}$ is $\mathrm{mL} / \mathrm{g}$ which gives a slope of the linear sorption isotherm (Tandlich and Balaz, 2011) Linear sorption isotherms have been reported by Tandlich and Balaz (2011) for biphenyl on the illite-rich soil from North Dakota and a commercial sodium bentonite sample. On the illite-rich soil, the $K \mathrm{~d}$ value for biphenyl was equal to $42.7 \pm 1.8 \mathrm{~mL} / \mathrm{g}$ after 6 days and this value increased to $120 \pm 8 \mathrm{~mL} / \mathrm{g}$ after 21 days of the sorbate/sorbent contact time. With the commercial sodium bentonite (montmorillonite), the $K_{\mathrm{d}}$ value was virtually independent of the contact time, as the respective $K_{\mathrm{d}}$ value was equal to $20.3 \pm 0.3 \mathrm{~mL} / \mathrm{g}$ after 6 days and to $23.0 \pm 1.1 \mathrm{~mL} / \mathrm{g}$ after 21 days of sorbent-sorbate contact. After normalisation to the solid/liquid ratios for both sorbents, the six-day contact time, most likely resulted in the sorption onto the internal surface of the clay mineral crystal lattice, while the 21 days period indicated when the soil organic carbon become the dominant sorption site for aromatic HOCs (Tandlich and Balaz, 2011). For other HOCs besides biphenyl, such sorption behaviour could be described as a combination of linear and Freundlich isotherms that can be observed at low organic carbon concentrations (Kalinovich et al. 2012).

Groisman et al. (2004), found that nonylphenol, if sorbed onto the surface of kaolinite at concentrations of $1.0 \mathrm{mg} / \mathrm{L}$, inhibited successive sorption of phenanthrene which is a polyaromatic hydrocarbon. If the dissolved concentration of nonylphenol in the aqueous phase reached $10 \mathrm{mg} / \mathrm{L}$ and this solution was in contact with kaolinite prior to phenanthrene sorption, then the apparent $K_{\mathrm{d}}$ values for phenanthrene increased in comparison to the 1.0 $\mathrm{mg} / \mathrm{L}$ conditioning (Wang et al. 2009). The most likely explanation for this observation is that at the initial nonylphenol concentration of $1.0 \mathrm{mg} / \mathrm{L}$, the surfactant and phenanthrene were sorption antagonists. On the other hand, if the initial nonylphenol concentration increased to $10 \mathrm{mg} / \mathrm{L}$, then enough surfactant was likely sorbed onto the kaolinite surface to form nonylphenol hemimicelles or micelles there. If this was the case, then micellial nonylphenol structures would have formed a hydrophobic phase at the kaolinite surface, i.e., thus facilitating increased sorption partitioning of the phenanthrene molecules onto the kaolinite surface. The presence of microbial cells on the surface of the soil mineral phase has been shown to influence phenanthrene sorption. Thus, the combination of the kaolinite with surfactants could provide a viable remediation technology for HOC elimination from the environment (He et al. 2010). 


\section{The Ion Exchange Isotherms}

The mineral species (charged in aqueous solution) are mainly attracted by the surface charges of the solid driven by adsorption of competing ion exchange phenomena. The composition of the bulk solution is considered constant and a single-species isotherm can be applied when the concentration of the studied ion is lower than the competing ion, although this is strongly dependent on the composition of the bulk solution. However, when the concentration of the studied ion reaches the same order of magnitude as other competing ions, the composition of the bulk solution can no longer be considered constant and a multi species isotherm is needed. It is possible to take into account the competition between several ions with modified multi-species isotherms. Graham, (2000) simulated the consequences of different competition features on the shape of multi-species equilibrium or kinetic 1Freundlich and Langmuir isotherms. The ion exchange isotherm is another way to describe the competition between two or more ions when their range of concentration is wide. This specific isotherm does not describe $\mathrm{Q}$ versus $\mathrm{C}$, but the molar fraction of charges $\mathrm{eE} \mathrm{k}$ of the ion $\mathrm{k}$ adsorbed on the solid $\left(\left(\right.\right.$ molc $\left.\mathrm{kg}^{-1}\right) /\left(\right.$ molc $\left.\left.\mathrm{kg}^{-1}\right)\right)$ versus the molar fraction of charges Ek of the ion $\mathrm{k}$ remaining in solution $\left(\left(\right.\right.$ molc L$\left.^{-1}\right) /\left(\right.$ molc L$\left.\left.^{-1}\right)\right)$. It is also assumed that adsorption sites (surface charges of the solid) are constant, and is called the "intrinsic charge" rint (molc $\mathrm{kg}^{-1}$ ). For a cation exchange, the adsorption capacity 1depends on the exchange capacity (anion exchange capacity). It is important to note that the cation or anion exchange capacity is an operational parameter and not an intrinsic property of adsorption. So, it cannot be defined as print, which is a conceptual parameter. The measurement is dependent on conditions such as $\mathrm{pH}$ or ionic strength (Bloom and Mansell, 2001).

\section{Surface complexation models}

The surface complexation models are based on inner or outer sphere complexation which can be distinguished by the way they represent the distribution of the electric potential around the charged surfaces from each other. The main historical models are: 51the triple- layer model, the constant capacitance model, the Stern variable surface charge model, the one-pK model, the generalized two layer model and the charge distribution model. Good reviews have been written on the physical bases and experimental applications of surface complexation models.

\section{Oswin model:}

It is an empirical model that consists in a series expansion for sigmoid shaped curves and it was developed by Oswin (Oswin, 1946). It is described in this equation:

$$
M_{w}=C\left(\frac{a_{w}}{1+a_{w}}\right)^{n}
$$

where $\mathrm{C}$ and $\mathrm{n}$ are constants. The Oswin equation was used to relate the moisture content of fat free dry milk and freeze dried tea up to a water activity of 0.5 (Oswin, 1946,), as well as for various foods.

\section{Smith model (1947)}

The Smith model describes the final curved portion of water sorption isotherm of high molecular weight biopolymers. He assumed that there are two fractions of water that are sorbed onto a dry surface; the first fraction exhibits a higher condensation heat than the 
normal and it would be expected to follow the Langmuir model. Smith based his model on the second fraction, which only can be formed after the first fraction has been absorbed. He considered that the second fraction consists of multilayers of condensed water molecules, which effectively prevent any possible evaporation of the initial layer. He theorized that the moisture content in the second fraction was 1proportional to the logarithm of the difference between the law of the sample and pure water (Sahin and Gülüm ,2006, Da Silva, et al ., 2002). This 31 model can be written as:

$$
M_{w}=C_{1}+C_{2} \ln \left(1-a_{W}\right)
$$

where $\mathrm{C} 1$ is the quantity of water in the first sorbed fraction, and $\mathrm{C} 2$ is the quantity of water in the multilayer moisture fraction. 38This equation could be used in the water activity range from 0.5 to 0.95 in the case of wheat desorption (Moraes, 2008) and for various products.

\section{Halsey model}

This model provides an expression for the condensation of multi layers at a relatively large distance from the surface, assuming that the potential energy of a molecule varies as the inverse $\mathrm{n}^{\text {th }}$ power of its distance from the surface. This equation is a good representation of adsorption data regarding isotherms type I, II, or III. Moreover, this equation described the sorption behaviour of food products that contain starch (Levine and Slade, 1991).

$$
M_{w}=M_{0}\left(-\frac{A}{R T \ln a_{w}}\right)^{1 / n}
$$

This model is described as it is expressed in this equation: (51) where A and $\mathrm{n}$ are constants; $\mathrm{R}$ is the universal gas constant; $\mathrm{T}$ is the absolute temperature; and $\mathrm{M}_{0}$ is monolayer moisture content. Since the use of the RT term does not eliminate the temperature dependence of A and $n$, the Halsey equation was modified by Iglesias and Chirife, (1976) into the following form, as it is described in equation:

$$
M_{w}=\left(-\frac{c}{\ln a_{w}}\right)^{1 / n}
$$

where $\mathrm{C}$ and $\mathrm{n}$ are constants.

Guggenheim-Anderson-de Boer (GAB) model: The term GAB model comes from the names Guggenheim, Anderson and De Boer, who independently derived the equation in 1966, 1946 and 1953, respectively. This model has a viable theoretical background since it is a refinement of Langmuir and BET theories of physical adsorption, it provides a good description of the sorption behaviour of almost every food product (aw - 0.9); its parameters have a physical meaning 9in sorption processes; and it describes the effects of temperature on isotherms by means of Arrhenius type equations (Al-Muhtaseb, et al., 2002, Lomauro, et al., 1985).

$$
\frac{M_{w}}{M_{O}}=\frac{(C-1) K a_{w}}{\left(1-K a_{w}+C K a_{w}\right.}+\frac{K a_{w}}{1-K a_{w}}
$$


This model postulates that the state of sorbate molecules in the second layer is identical to the one in superior layers, but different from those of the liquid state. The authors introduced a second sorption stage of the molecules of a sorbate that was differentiated as a good sorbate. This isotherm necessarily contains a third constant, $\mathrm{k}$, which measures the difference of the chemical potential standard between the molecules of this second stage and those of the pure liquid state. The GAB model is expressed as:

$$
\left.M_{w}=\frac{M_{O} C K a_{w}}{\left(1-K a_{W}\right)\left(1-K a_{w}+C K a_{w}\right)}\right)
$$

Where $\mathrm{M}_{0}$ is the monolayer moisture content; $\mathrm{C}$ and $\mathrm{K}$ are the adsorption constants, which are related to the energies of interaction between the first and the further sorbed molecules at the individual sorption sites. They can be theoretically expressed as it is expressed in equation 55 and equation 56.

$$
\begin{aligned}
& C=c_{0} \exp \left(\frac{H_{O}-H_{n}}{R T}\right) \\
& C=k_{0} \exp \left(\frac{H_{n}-H_{1}}{R T}\right)
\end{aligned}
$$

where $\mathrm{C}_{0}$ and $\mathrm{k}_{0}$ are the entropic accommodation factors; $\mathrm{H}_{0}, \mathrm{H}_{\mathrm{n}}$, and $\mathrm{H}_{1}$ are the molar sorption enthalpies of the monolayer, the multilayers on top of the monolayer, and the bulk liquid, respectively. $\mathrm{R}$ is the ideal gas constant and $\mathrm{T}$ is the absolute temperature. Note that when $\mathrm{K}$ is 1 .

\section{Peleg model}

This model is a four-parameter model described in equation below:

$$
M_{W}=C_{1} a_{w}^{c 3}+C_{2} a_{w}^{c 4}
$$

where $\mathrm{C}_{1}, \mathrm{C}_{2}, \mathrm{C}_{3}$, and $\mathrm{C}_{4}$ are constants; $\mathrm{C}_{3}<1$ and $\mathrm{C}_{4}>1$. The model does not have a monolayer incorporated in it. The Peleg model adequately described the moisture sorption isotherms of pesticides.

\section{Effect of Hydration of the Sorbent and Medium of Sorption.}

Hydration affects the SOM structure and thus any antagonism of HOC mixtures binding to the SOM. Hydration can stimulate the occurrence of non-covalent interactions such as hydrogen bonds, their significance in sorption can be deduced from sorption of HOCs with varying structures from $n$-hexadecane (Borisover and Graber, 2003). Use of this solvent eliminates the influence of polarizability of the tested HOCs on their sorption onto covalent compounds. Under the same conditions, the effect of the compound's structure on its sorption onto the NOM can be elucidated, along with the structural features in the NOM structure being characterized (He et al. 2010). 
Huang, (2003) concluded from the sorption data that the sorption of HOCs from the water system was much higher than the sorption from the hydrocarbon system due to an increased number of sorption sites in the covalent bond upon hydration. The hydrated bond structure contains more water molecules than the air-dried matrix. This leads to more hydrogenbonding potential and thus provides for the increased sorbate mass transfer through/into the structure based on hydrogen bonds (Graber et al. 1998).

Such hydration is facilitated by the presence of hydrogen-bonding groups, such as $\mathrm{COOH}$ in the structure of the Pahokee peat in his studies. This in turn increases the number of available sorption sites upon hydration of Pahokee peat more, than upon its solvation with organic solvent. More sorption sites lead to higher sorption capacities, i.e., likely resulting in the linear sorption isotherms under conditions of hydration of Pahokee peat in aqueous environments. Similar solvation does not take place in the $n$-hexadecane, thus lowering sorption uptake for phenol and pyridine (Graber et al. 1998).

These conclusions about the role of hydration in the sorption of HOCs onto the soil organic carbon/matter are supported by the findings of Borisover and Graber, (2002). They examined the sorption of $\mathrm{m}$-nitrophenol from $\mathrm{n}$ hexadecane, m-nitrophenol from hexane, nitrobenzene from hexadecane and acetophenone from n-hexadecane, benzyl alcohol from n-hexadecane onto NOM. N Hexadecane and n-hexane are hydrophobic and were considered the dry inert systems. It was found that the sorption of organic compounds from hydrocarbon solutions on dried NOM was much slower as compared to sorption of organic compounds by the NOM sorbent from water. This is demonstrated by the observation that the apparent sorption equilibrium for m-nitrophenol was reached at about $50 \mathrm{hrs}$ from the aqueous phase as compared to between 300 and 600 hours in n-hexane and 700 hours in n-hexadecane. They attributed this to the poor solvation of the sorbent in the hydrocarbon phase resulting in the "rigidity" of the sorbent, i.e., formation of new sorption sites for hydrogen bonding compounds in the hydrated Pahokee peat as compared to peat exposed to the dry peat matrix. Graber, (1998) examined twelve systems with the following combination of sorbate/sorbent/solvent; m-nitrophenol/humic acid/water, m-nitrophenol/humic acid/n hexadecane, m-nitrophenol/humin/water, m-nitrophenol/humin/n-hexadecane, nitrobenzene/humic acid/water, nitrobenzene/ humic acid/n-hexadecane, nitrobenzene/humin/water, nitrobenzene/humin/n-hexadecane, acetophenone/humin/water, acetophenone/humin/n-hexadecane, benzyl alcohol/humin/water, and benzyl alcohol/humin/n-hexadecane. From their study, the authors concluded that hydration of the NOM may cause up to 2-3 orders of higher sorption of organic compounds in comparison to wetting by hydrocarbon solvents. Acetophenone and benzyl alcohol sorption was higher in the aqueous conditions as compared to n-hexadecane. Lower polarity of the HOCs resulted in stronger sorption to dry humin, as demonstrated by the strength of sorption to dry humin decreased in the following order: nitrobenzene >m-nitrophenol > acetophenone > benzyl alcohol. Sorption of compounds with strong specific interactions, such as H-bonding (benzyl alcohol, $\mathrm{m}$ nitrophenol), is significantly influenced by hydration. For acetophenone and nitrobenzene there was a decrease in sorption upon hydration, whereas the opposite was recorded for benzyl alcohol and m-nitrophenol. Thus, hydration of NOM or SOM leads to formation of new sorption sites, but access to them is controlled by the sorbate's molecular volume and its functional groups. 


\section{Effects of Temperature, Ionic Strength and pH on the HOCs' Sorption}

The above parameters are major factors that affect the sorption of hydrophobic organic contaminants in the environment. Variation in any of these parameters could alter the sorption of these HOCs.

In a study to determine the effects of temperature on sorption by Zhang and Zheng, (2009), the Freundlich isotherm best described the sorption data of naphthalene and phenanthrene onto soils between 15 to $35^{\circ} \mathrm{C}$. It was noted that $n$ was directly proportional to the incubation temperature as it increased from 0.713 to 0.893 for naphthalene and from 0.550 to 0.756 for phenanthrene, respectively. $K_{\mathrm{f}}$ for naphthalene decreased from 106.8 to 42.8 in the respective units, while the $K_{\mathrm{f}}$ value for phenanthrene decreased from and 932.7 to $568.9(\mathrm{~mL} / \mathrm{g})^{0.55-0.893}$ (Zhang and Zheng, 2009). According to Equation (49) $K_{f}$ and $n$ are isotherm constants for a given sorbate and sorbent; and they indicate the capacity and intensity of the sorption at a given and constant temperature. Zhang and Zheng also reported that as temperature increases $n$ increases, i.e., the solute-solvent interaction strength increases which in turn leads to a decrease in $K_{f}$. Similarly, an inverse correlation between the temperature and the sorption partition coefficient normalized to the soil organic carbon content $\left(K_{o c}\right)$ was reported. The most common explanation is the increase in the solute's relative affinity for the liquid phase in comparison to the solid phase. The effect of $\mathrm{pH}$ has been studied mainly in the soil/aqueous systems. The effects $\mathrm{pH}$ on the sorption of 4-phthalic acid ester, dimethyl phthalate (DMP), diethyl phthalate (DEP), diallyl phthalate (DAP) and di- $n$-butyl phthalate (DBP), on three soils have been studied by (Yang et al 2013). The aqueous phase $\mathrm{pH}$ was set to $4.0,5.5,7.0,8.5$ and 10.0. An increase in $\mathrm{pH}$ leads to the decrease in the $K_{f}$. $\mathrm{pH}$ 4.0, the maximum $K_{\mathrm{f}}$ values were observed, and thus the sorption capacity of the soils for phthalic esters, was indirectly proportional to the aqueous phase $\mathrm{pH}$ (Yang et al. 2013). This was attributed to the increase in the dissociation/ionisation of the functional groups on SOM which leads to the increase in the charge in the SOM structure. This resulted in the decreased sorption of phthalic esters to the soils studied as these are non-ionised HOCs. Similar observations were reported in other studies (You et al. 1999).

The $K_{f}$ values of the phthalic acid ester in relationship to $\mathrm{pH}$ (adapted from reference

$\begin{array}{lllll}\text { Compound } & \text { DMP Kf } & \text { DEP Kf } & \text { DAP Kf } & \text { DBP Kf } \\ \text { pH 4.0 } & 5.31 & 9.87 & 33.1 & 161 \\ \text { pH } 5.5 & 4.64 & 8.59 & 28.3 & 147 \\ \text { pH 7.0 } & 3.18 & 6.38 & 21.7 & 128 \\ \text { pH } 8.5 & 2.70 & 5.85 & 19.6 & 97.2 \\ \text { pH 10.0 } & 2.54 & 5.85 & 18.3 & 91.3\end{array}$

Salting out effect, increases the apparent sorption of non-ionic HOCs into kaolinite in the case of increased aqueous phase ionic strength observed for endrin by Peng et al. (2009). The sorption isotherm was linear and troughs were observed at $\mathrm{pH}=5.4$ Hydrophobic and iondipole interactions were found to the main non-covalent interactions involved in the endrin sorption to kaolinite (Peng et al. (2009). Finocchiaro et al. (2005), examined the relationship 
between the following soil properties: $\mathrm{pH}$, the organic carbon concentration, the content of amorphous iron oxides and the content of clays, and the soil sorption uptake of molinate, terbuthylazine, bensulfuron methyl and cinosulfuron. Extent of sorption of molinate and terbuthylazine was directly proportional to the concentration of organic carbon and the content of amorphous iron oxides (Behra, et al. 2003). On the other hand, sorption of bensulfuron-methyl is a function of the soil $\mathrm{pH}$, the organic carbon concentration and the clay content. Finally, the cinosulfuron sorption was positively correlated with the soil $\mathrm{pH}$. (Behra et al. 2003). Thus all these variables together with the covalent structure of the HOCs must be taken into account when conducting a sorption experiment

Behra et al. 2003 showed that tributyltin sorbed onto mineral surfaces via cation exchange of the monovalent cation of the tin complex for $\mathrm{H}^{+}$and $\mathrm{Na}^{+}$, if the $\mathrm{pH}$ of the aqueous phase was equal to 6.0 or less. Sorption capacities of the mineral surface for cationic version of tributyltin decreased from pure quartz $>$ treated sand $>$ natural sand $>>$ kaolinite.

\section{CONCLUSION}

Models for the sorption isotherms were discussed with the 3 common approaches to the great diversity of retention/release phenomena. However, this approach is macroscopic and empirical in nature, thus not saying, by itself, anything on the complicated mechanisms involved. Other methods allow the investigation of the retention microscopically, particularly with spectroscopic and microscopic tools. They have provided a new efficient way to verify several assumptions used in isotherm interpretations on the solid structure and retention/release mechanisms thereby giving more confidence in structure-based and mechanism-based complexation models. These models are efficient compared to the traditional " $\mathrm{Kd}$ " approach. However, natural media such as complicated mixtures of numerous mineral and organic compounds "sorption isotherm" will be still used for a long time. The work covered isotherms and models such as distribution coefficient, the Langmuir isotherm, the Freundlich isotherm, and ion exchange, the constant capacitance, the diffuse layer, Oswin, Smith, Halsey, Peleg, Guggenheim-Anderson-de Boer (GAB) and triple layer model. These Models describes the sorption isotherms of hydrophobic contaminants.

\section{Acknowledgement}

I acknowledge the Department of Chemistry University of Jos, and Department Science Laboratory Technology, their library was very instrumental, with Journal textbook materials, thank you and God Bless.

\section{REFERENCES}

Al-Muhtaseb A.H, McMinn W.A.M and Magee T.R.A., (2002). 5 Moisture sorption isotherm characteristics of food products: A review.Food Bioprod, Process; 80(2): 118-128. Anderson, P.R.. and Axe, L.,(1997). Experimental and theoretical diffusivities of Cd and $\mathrm{Sr}$ in hydrous ferric oxide. Journal of Colloid. Barrow, N. J. and Bowden J. W (1987). A comparison for describing absorption of anion on a variable charge mineral surface, Journal colloid Interface Science, 236 - 250. 1 
Behra P., Lecarme Theobald E., Bueno M. and Ehrhardt J.J.(2003). sorption of tributyltin onto a natural quartz sand. Journal of Colloid Interface. Science; 263:4-12.

Benjamin, M.M (2002). Water Chemistry, New York: McGraw-Hill. 23-29.

Blahovec J, and Yanniotis S. (2009). Modified classification of sorption isotherms. Journal of Food Engineering. 91 (1): 72-77

Borisover M. and Graber E.R. (2003). Classifying NOM-organic sorbate interactions using compound transfer from an inert solvent to the hydrated sorbent Environmental Science Technology, 37:5657-5664.

Bowden, J .N, Nagarajah, S, Barrow N. J, Posner, A. M. and Quirk, J. P. (1981). Describing the adsorption of Phosphate, Citrate and Selenite on a variable charge mineral surface. Australian Journal of soil research. 18, 49-60

Brunauer S, Deming L.S. and Teller E (1940). On a theory of Van der Waals adsorption of gases. Journal of American Chemical Society; 62 (7): 1723-1732.

Cass T. M and Walter J. W. Jr. (1986). The Netherlands 9 Sorption of Hydrophobic Organic Pollutants in Saturated Soil Systems. Journal of Contaminant Hydrology, 1(243-261) Elsevier Science Publishers B.V., Amsterdam). 1

Clark Ehlers G.A., Forrester S.T., Scherr K.E., Loibner A.P. and Janik L.J (2010). Influence of the nature of soil organic matter on the sorption behaviour of pentadecane as determined by PLS analysis of mid-infrared DRIFT and solid- state 13C NMR spectra. Environ. Pollut. 2010;158:285-291.

Chiou C.T., McGroddy S.E.and Kile D.E (1998). Partition characteristics of polycyclic aromatic hydrocarbons on soils and sediments. Environmental Science Technology, 32:264-269.

Chu B., Goyne K.W., Anderson S.H., Lin C.H. and Lerch R.N. (2013). Sulfamethazine Sorption to soil: Vegetative management, $\mathrm{pH}$, and dissolved organic matter effects. J. Environ. Qual. 2013;42:794-805.

Davis, J. A and Leckie, J. O. (1978). Surface Ionization And Complexation At The Oxide/Water Interface II. Surface Properties of Amorphous Iron Oxyhydroxide and Adsorption of Metal Ions. Journal of Colloid interface. 67, 90 - 107.

Da Silva M, Gouveia J. and Almeida F.,(2002). Desorption and isosteric heat of mango pulp. Rev Bras Eng Agríc Ambient; 6(1): 123-127

Delle Site, A., 2001, Factors 39 affecting sorption of organic compounds in natural sorbent/water systems and sorption coefficients for selected pollutants. a review. J. Phys. Chem. Ref. Data. 30, 187-439.

Ding, L, Marinas, B.J, Schideman, L.C, Snoeyink, V.L. (2006). Competitive effects 6of natural organic matter parameterization and verification of the three-component adsorption model. Environment Science Technology, 40: 350-356.

Dzombak, D.A. and F.M.M. Morel, (1990). Surface Complexation Modeling: Hydrous Ferric Oxide, John Wiley and Sons, New York. 1

Finocchiaro R., Meli S.M., Cignetti A. and Gennari M. (2005). Adsorption of molinate, terbuthylazine, bensulfuron-methyl, and nicosulfuron on different Italian soils. Fresen. Environ. Bulletin, 14:690-697.

Francis M, Roman Tandlich, Brendan S. Wilhelmi and Stefan Balaz.(2014). Sorption of Hydrophobic Organic Compounds on Natural Sorbents and Organoclays from Aqueous and Non-Aqueous Solutions: A Mini-Review, International Journal of Environmental Research and Public Health, 11, 5020- 5048.

Freundlich, H.(1909). Kapillar Chemie. Akademische Verlagsgesellschaft, Leipzig, Germany. 
Gerstl, Z. (1990). Estimation of organic chemical 9sorption by soils. J Contam Hydrol;6: 357-375.

Girvin, D.C, Scott, A.J. (1997). 55Polychlorinated biphenyl sorption by soils: measurement of soil-water partition coefficients at equilibrium. Chemosphere;35: 2007-2025.

Goldberg, S.R., 1992. Use of surface complexation models in soil chemical systems. Adv. Agron. 47, 233-329.

Graber E. and Borisover M. (1993).1Hydration-facilitated sorption of specifically interacting organic compounds by model soil organic matter, Environmental Science and Technology, 32:258-263).

Graham MR, Summers RS, Simpson MR, MacLeod BW (2000). Modelling equilibrium adsorption of 2-methylisoborneol and geosmin in natural waters. Water Resources;34:2291-2300.

Grathwohl, P., (1990).1Influence of organic matter from soils and sediments from various origins on the sorption of some chlorinated aliphatic hydrocarbons: Implications on Koc correlations. Environmental. Science and Technology. 24, 1687-1693.

Groisman, L., Rav-Acha, C., Gerstl, Z and Mingelgrin, U.,(2004).Sorption of organic compounds of varying hydrophobicities from water and industrial wastewater by long and short chain organoclays. Applied Clay Science. 24, 159-166.

Gupta V.K, Carrott, P.J.M, Ribeiro, Carrott, M.M.L, (2009). Low-cost adsorbents: growing approach to wastewater treatment - a review. Environmental Science and Technology, 39:783-842.

Hayes, K.F., G. Redden, W. Ela, and J.O. Leckie (1991). 48Surface complexation models: An evaluation of model parameter estimation using FITEQL and oxide mineral titration data. Journal. natural waters. American. Chemical. Society. Advance in. Chemistry Ser. 189:1-31.

He M., Zhang J., Wang Y., Jin L (2010). 1Effect of combined Bacillus subtilis on the sorption of phenanthrene and 1,2,3-trichlorobenzene onto mineral surfaces. Journal. Environmental Quality, 39:236-244.

Hu, Y.; Qi, S.; Zhang, J.; Tan, L.; Zhang, J.; Wang, Y.; Yuan, D (2011). Assessment of organochlorine pesticides contamination in underground rivers in Chongqing, Southwest China. Journal Geochemistry. Exploration, 111, 47-55.

Huang, W.; Peng, P.; Yu, Z.; Fu, J (2003). Effects of organic matter heterogeneity on sorption and desorption of organic contaminants by soils and sediments. Appl. Geochemistry, 18, 955-972.

Jiuhui Q. U. (2008) Research progress of novel adsorption processes in water purification: A Review. Journal of Environmental Sciences. 20(1) 1-13.

Kalinovich, I.; Allen-King, R.M.; Thomas, K (2012). Distribution of carbonaceous matter in lithofacies: Impacts on HOC sorption nonlinearity. J. Contam. Hydrol.133, 84-93.

Karickhoff, S.W. (1981). Semi-empirical estimation of sorption of hydrophobic pollutants on natural sediments and soils.Chemosphere, 10, 833-846.

Karickhoff, S.W., (1980). Sorption kinetics of hydrophobic pollutants in natural sediments. In: R.A. Baker (Editor), Contaminants and Sediments, Ann Arbor Science Publishers, Ann Arbor, Mich., 193--205.

Karickhoff, S.W., Brown, D.S. and Scott, T.A., (1979). Sorption of hydrophobic pollutants in natural sediments. Water Resource. 13: 231--248.

Krauss, M.; Wilcke, W (2005). Persistent organic pollutants in soil density fractions: Distribution and sorption strength. Chemosphere, 59, 1507-1515. 
Langmuir, I., (1918). The adsorption of gases on plane surfaces of glass, mica, and platinum. Journal of Analytical Chemistry Society. 40, 1361-1403.

Levine H, Slade L (Eds). (1991). Water Relations in Foods. New York, United States: Plenum Press. 56Van den Berg C. Food-water relations: Progress and integration, comments and thoughts; 22-25

Limousin, G., J. P. Gaudet, J., Charlet L, Szenknect, S, Barthe, V. and Krimissa M (2007). Sorption isotherms: A review on physical bases, modeling and measurement

Lomauro CJ, Bakshi AS, Labuza TP.,(1985). Evaluation of food moisture sorption isotherm equations, Part I: Fruit, vegetable and meat products. Lebensm Wiss Technology, 18 (2): 111-117. 2

Manz M., Wenzel K and Dietze U., Schuurmann G. Persistent organic pollutants in agricultural soils of central Germany. Science Total Environment. 2001;277:187-198.

Oswin, C.R. (1946). The kinetics of package life. III. Isotherm. Journal Society Chemistry, Dec; 65 (12): 419-421.

Oudou H.C., Bruun Hansen H.C. (2002). 1Sorption of cypermethrin diastereoisomers to quartz, corundum, goethite, kaolinite and montmorillonite. International Journal Environment. Analytical Chemistry. 82:529-544.

Peng X., Wang J., Fan B., Luan Z (2009). Sorption of endrin to montmorillonite and kaolinite clays. Journal of Hazardous Material. 168:210-214)..

Pignatello, J. J. (2001) The measurement and interpretation of sorption and desorption rates for organic compounds in soil media. Adv. Agron. 69, 1-73

Ren S. and Schultz T.W. Identifying the mechanism of aquatic toxicity of selected compounds by hydrophobicity and electrophilicity descriptors. Toxicology. Letter. 129:151-160.

Sahin S, and Gülüm S. (2006). Physical Properties of Foods. New York, United States. 205, 218.

Schwarzenbach, R. P., Gschwend, P. M., Imboden, D.M. (2003). 66Environmental organic chemistry. 2nd Ed.Wiley: New York.

Schwarzenbach R. P., Westall J. (1981): Transport of nonpolar organic compounds from surface water to groundwater: Laboratory sorption studies. . Environmental Science and Technology. 5, 1360-1367.

Sigg, L. and 20Stumm, W. (1981). The interaction of anions and weak acids with the hydrous goethite $(\alpha-\mathrm{FeOOH})$ Surface. Colloid Surface. 2, $101-117$.

Sircar, S, Basic research needs for design of adsorptive gas separation processes Industrial and engineering chemistry research 45 (16), 5435-5448

Smith J. A., Witkowski P. J., Fusillo T. V. (1988): 42Manmade organic compounds in the surface waters of the United States - A review of current understanding. U.S. GS Circular 1007, U.S. Geological Survey Denver, Co.

Sposito, G. (1981). Cation Exchange in Soils: An Historical and Theoretical Perspective, ASA Spect, Publ , 40, 13-28 20

Stumm, W., Kummert, R., Sigg, L., (1980). A ligand exchange model for the adsorption of inorganic and organic ligands at hydrous oxide interfaces. Croatia Chem Acta 53, 291312. 1

Tandlich R., Balaz S. (2011). Different clay minerals and biphenyl sorption in soils. African Journal of Agricultural Resources. 6:2321-2328. 
Tandlich, R (2004). Microbial PCB Degradation and Binding to Soil Components. Ph.D. Thesis, North Dakota State University, Fargo, ND, USA, 23 January.

Tien, C. (1994) Adsorption calculations and modeling. Butterworth-heinemann series in chemical engineering, Butterworth Heinemann, Boston.

Van Riemsdijk, W. H, Bolt, G. H, Koopal, L. K. and Blaakmecn J. (1986). 61Electrolyte adsorption on heterogeneous surfaces. Adsorption Models. Journal of colloids interface science, 109, $219-228$.

Wang L., Sun H., Wu Y., Xin Y. (2009). Effect of sorbed nonylphenol on sorption of phenanthrene onto mineral surface. Journal Hazard. Material. 161:1461-1465.

Xia, G., Pignatello, J. (2001), Detailed Sorption Isotherms of Polar and Apolar Compounds in a High-Organic Soil. . Environmental 49 Science and Technology. 35, 84-94.

Yang F., Wang M., Wang Z. (2013). Sorption behavior of 17 phthalic acid esters on three soils: Effects of $\mathrm{pH}$ and dissolved organic matter, sorption coefficient measurement and QSPR study. Chemosphere. 93:82-89

Yang, Y., Hawthorne, S. B., Miller, D. J., Liu, Y., Lee, M. L. (1998), 62 Adsorption versus absorption of polychlorinated biphenyls onto solid-phase microextraction coatings. Analytical Chemical. 70, 1866-1869. 1

You S., Yin Y., Allen H.E. Partitioning of organic matter in soils: Effects of pH and water/soil ratio. Science Total Environment. 227:155-160.

Zhang J., Zeng J., He M. Effects of temperature and surfactants on naphthalene and phenanthrene sorption by soil. J. Environ. Sci. China. 2009;21:667-674. doi: 10.1016/S1001-0742(08)62297-4,

Zung J.P (2002). Isoterma de sorción de tres etapas y modelos de sorción restringida. Buenos Aires, Argentina: Universidad de Buenos Aires; 2, 14. 35 